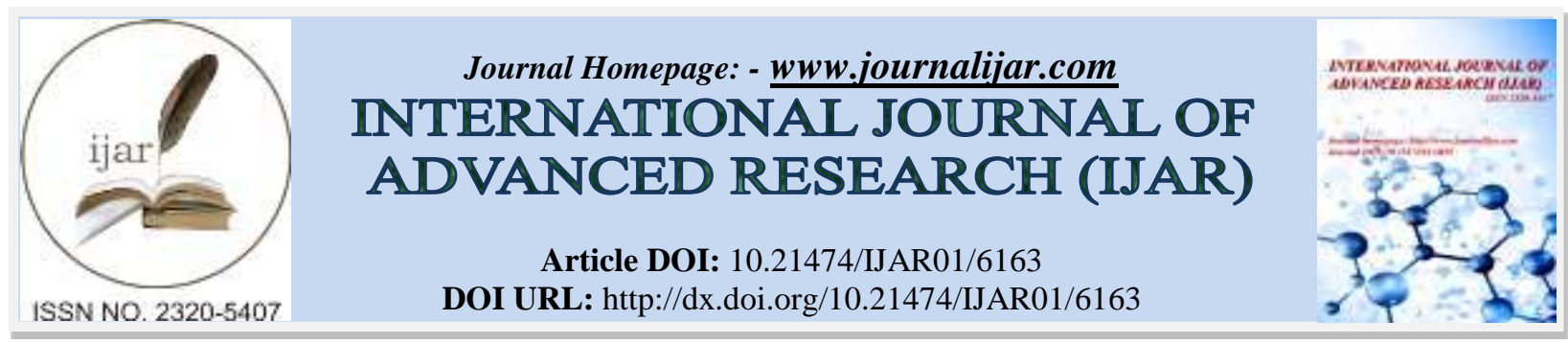

RESEARCH ARTICLE

\title{
A STUDY ON DEPRESSION, ANXIETY AND STRESS LEVEL AMONG MEDICAL STUDENTS OF GAUHATI MEDICAL COLLEGE, GUWAHATI, ASSAM.
}

\author{
Dr. Rupali Baruah ${ }^{1}$, Dr. Saras Sanchaya ${ }^{2}$ and Dr. Jutika Ojah ${ }^{3}$. \\ 1. Professor, Department of Community Medicine, GMCH, Guwahati. \\ 2. PGT, Department of Community Medicine, GMCH, Guwahati. \\ 3. Professor and Head, Department of Community Medicine, GMCH, Guwahati.
}

\section{Manuscript Info}

\section{Manuscript History}

Received: 25 October 2017

Final Accepted: 27 November 2017

Published: December 2017

\begin{abstract}
Introduction: The mental health of medical students is an area of increasing concern worldwide. The presence of psychological morbidity in medical students has been reported from various countries across the world. There are very few Indian studies regarding this topic. Objective: To study on depression, anxiety and stress level among medical students of Gauhati Medical College, Guwahati, Assam. Methodology: A cross sectional study was done in Undergraduate students of Gauhati Medical College. Total 471 undergraduate medical students were in the study. Results: Univariate analysis showed that higher scores of depression, anxiety and stress was associated with female gender, lower semester, and non-smokers. Students who were satisfied with their education had lower depression, anxiety and stress scores. Though the scores were higher among non-alcoholics the difference was not significant. Conclusion: Medical college training is intended to prepare graduates for a personally rewarding and socially meaningful career. However, reports have shown that this is a time of great personal distress for physicians-in-training. Therefore, there is an urgent need for the counseling services to be made available to the students in the medical college to control this morbidity.
\end{abstract}

Copy Right, IJAR, 2017,. All rights reserved.

\section{Introduction:-}

Stress is a state of an individual that results from the interaction of the individual with the environment that is perceived as threatening to the well-being. It is an external constraint which directly upsets the individual both mentally and physically. ${ }^{[1]}$ Medical education is highly challenging and often places heavy demands on the mental resources of its students; stretching their psychological distress and making them vulnerable to high levels of negative affective states. Compared to other education; medical education is evidenced by high prevalence of stress. $^{[2]}$

The three main stressors identified are examinations, work and financial responsibilities. Several other factors such as curriculum, traumatic events related to patients, ethical dilemmas also make them vulnerable to depression. ${ }^{[3]}$ Gender, lack of family support, are also one of the risk factors. ${ }^{[4]}$ Students exposed to work overload in a competitive environment with constant pressure of assessment brings various changes in their daily habits such as lack of sleep, irregular diet, substance abuse. ${ }^{[5]}$ 
There are very few Indian studies regarding this topic in India. Keeping all these factors in mind, present study was done among undergraduate medical students of Gauhati Medical College, Guwahati.

\section{Materials and methods:-}

This was a cross sectional study in Undergraduate students of Gauhati Medical College from $15^{\text {th }}$ August 2016 to $15^{\text {th }}$ October, 2016. The study population was Undergraduate Medical students of Gauhati Medical College (all semesters). All students present on the day of study were included in the study. The data were collected using a previously validated and standardized tool, Depression Anxiety Stress Scale (DASS 42) and the associations with their personal characteristics such as smoking, drinking were analyzed. Incomplete DASS Scale questionnaire were not analyzed. A total of 471 undergraduate medical students were analyzed. The data collected were collected in MS Excel and then analyzed using Instat Graphpad.

\section{Results:-}

Table 1 shows the severity distribution of DASS scores with different subscales of depression, anxiety and stress. In depression subscale, $68.9 \%$ males and $46.9 \%$ females had normal depression score. Out of total students, 59\% had normal and $4 \%$ had extremely severe depression score. In anxiety subscale, 52.3\% males and $43.2 \%$ females had normal anxiety score. Out of total students, $48.2 \%$ had normal and $9.1 \%$ had extremely severe anxiety score. In stress subscale, $77.1 \%$ males and $56.8 \%$ females had normal stress score. Out of total students, $67.9 \%$ had normal and $2.3 \%$ had extremely severe stress score.

Table 1:- Severity distribution of DASS scores $(\%)$ among medical undergraduate students $(\mathrm{n}=471)$

\begin{tabular}{|l|l|l|l|l|l|l|}
\hline Subscale & Gender & Normal(\%) & Mild(\%) & Moderate(\%) & Severe(\%) & $\begin{array}{l}\text { Extremely } \\
\text { Severe(\%) }\end{array}$ \\
\hline Depression & All & $59.0 \%$ & $17.2 \%$ & $13.2 \%$ & $6.6 \%$ & $4.0 \%$ \\
\hline & Males & $68.9 \%$ & $15.9 \%$ & $7.8 \%$ & $5.0 \%$ & $2.3 \%$ \\
\hline & Females & $46.9 \%$ & $18.8 \%$ & $19.7 \%$ & $8.5 \%$ & $6.1 \%$ \\
\hline Anxiety & All & $48.2 \%$ & $10.2 \%$ & $22.1 \%$ & $10.4 \%$ & $9.1 \%$ \\
\hline & Males & $52.3 \%$ & $10.5 \%$ & $24.4 \%$ & $6.9 \%$ & $5.8 \%$ \\
\hline & Females & $43.2 \%$ & $9.9 \%$ & $19.2 \%$ & $14.6 \%$ & $13.1 \%$ \\
\hline Stress & All & $67.9 \%$ & $12.7 \%$ & $11.5 \%$ & $5.5 \%$ & $2.3 \%$ \\
\hline & Males & $77.1 \%$ & $11.2 \%$ & $6.6 \%$ & $3.5 \%$ & $1.6 \%$ \\
\hline & Females & $56.8 \%$ & $14.6 \%$ & $17.4 \%$ & $7.9 \%$ & $3.3 \%$ \\
\hline
\end{tabular}

Table 2 shows the univariate analysis of association with personal characteristics among undergraduate students. Out of 258 males and 213 females, the depression, anxiety and stress scores were higher in females and this association was statistically significant. Taking semester as variable, the different scores were also found to significantly associated. There was a decreasing trend in scores as the semester increased. Smoking was also significantly associated with lower scores in students who smoke. Taking drinking as the variable, lower scores were found in students who drink, although it was not statistically significant. Lower scores were found in students who were satisfied with education and this association was statistically significant.

Table 2:- Univariate analysis of association of DASS scores with personal characteristics among medical undergraduate students $(\mathrm{n}=471)$

\begin{tabular}{|l|l|l|l|l|}
\hline Variable & Categories(n) & Depression & Anxiety & Stress \\
\hline Gender & Male(258) & $9.30 \pm 7.97$ & $10.14 \pm 7.19$ & $14.00 \pm 7.88$ \\
\hline & Female(213) & $11.76 \pm 8.13$ & $12.27 \pm 6.18$ & $16.36 \pm 7.15$ \\
\hline & P value & P $<0.05$ & $\mathrm{P}<0.05$ & $\mathrm{P}<0.05$ \\
\hline Semester & $1^{\text {st }}(89)$ & $13.17 \pm 7.88$ & $12.50 \pm 7.13$ & $15.57 \pm 8.80$ \\
\hline & $3^{\text {rd }}(103)$ & $12.10 \pm 7.52$ & $12.18 \pm 6.95$ & $16.83 \pm 7.89$ \\
\hline & $5^{\text {th }}(108)$ & $13.65 \pm 7.19$ & $14.98 \pm 6.40$ & $17.19 \pm 7.54$ \\
\hline & $7^{\text {th }}(95)$ & $7.32 \pm 6.91$ & $7.86 \pm 5.15$ & $11.91 \pm 7.10$ \\
\hline & $9^{\text {th }}(76)$ & $4.18 \pm 5.12$ & $4.83 \pm 5.27$ & $8.18 \pm 5.22$ \\
\hline
\end{tabular}




\begin{tabular}{|c|c|c|c|c|}
\hline & $P$ value & $\mathrm{P}<0.001$ & $\mathrm{P}<0.001$ & $P<0.001$ \\
\hline \multirow[t]{3}{*}{ Smoking } & Yes (69) & $8.18 \pm 6.37$ & $9.13 \pm 7.19$ & $12.28 \pm 8.14$ \\
\hline & No (402) & $11.26 \pm 7.98$ & $11.56 \pm 6.97$ & $15.87 \pm 7.90$ \\
\hline & $\mathrm{P}$ value & $\mathrm{P}<0.05$ & $\mathrm{P}<0.05$ & $\mathrm{P}<0.05$ \\
\hline \multirow[t]{3}{*}{ Drinking } & Yes (155) & $9.94 \pm 7.18$ & $10.40 \pm 7.57$ & $13.78 \pm 8.30$ \\
\hline & No (316) & $11.19 \pm 8.16$ & $11.37 \pm 7.19$ & $14.93 \pm 8.19$ \\
\hline & $\mathrm{P}$ value & $\mathrm{P}>0.05$ & $\mathrm{P}>0.05$ & $P>0.05$ \\
\hline \multirow[t]{3}{*}{$\begin{array}{lll}\begin{array}{l}\text { Satisfied with own } \\
\text { education }\end{array} & & \\
\end{array}$} & Yes (392) & $9.89 \pm 8.12$ & $10.34 \pm 7.30$ & $14.11 \pm 8.45$ \\
\hline & No (79) & $13.14 \pm 8.69$ & $12.84 \pm 6.71$ & $17.37 \pm 8.38$ \\
\hline & $P$ value & $P<0.05$ & $\mathrm{P}<0.05$ & $P<0.05$ \\
\hline
\end{tabular}

\section{Discussion:-}

The present study indicates that females are more prone to depression, anxiety and stress. This corroborates with the study by Baldassin $\mathrm{S}$ et al who found out that females were more prone to depression. ${ }^{[4]}$

\section{Reference:-}

1. Salam A, Yousuf R, Bakar SM, Haque M. A systematic review of literatures. Int Med J 2013;20:649-55.

2. Jeong Y, Kim JY, Ryu JS, Kei L, Ha EH, Park H. The associations between social support, health related behaviours, socioeconomic status and depression in medical students; Epidemiol Health 2010;32.

3. Dyrbye LN, Thomas MR, Shanafelt TD. Systematic review of depression, anxiety, and other indicators of psychological distress among U.S. and Canadian medical students. Acad Med 2006;81:354-73.

4. Baldassin S, Alves TC, de Andrade AG, Nogueira Martins LA. The characteristics of depressive symptoms in medical students during medical education and training: A cross-sectional study. BMC Med Educ 2008 11;8:60.

5. Saharaian A, Javadpour A. Sleep disruption and it's correlation to pscychological distress among medical students. Shiraz E Med J 2010;11:12-7. 